Archived version from NCDOCKS Institutional Repository http://libres.uncg.edu/ir/asu/

\title{
Appalachïan
}

B O O NE, NORTH CAROLINA

\section{Individuals With Intellectual Disabilities: Educators in Expressive Arts Therapy}

By: Karen Caldwell, Ph.D., , Kathleen T. Brinko, Ph.D. , Rebecca

Krenz, M.A. , Kristin Townsend, M.A.

\begin{abstract}
The purpose of this qualitative study was to describe students' experiences during their participation in Express Yourself, an expressive arts service-learning program that partners university students from several different programs with adults with intellectual disabilities. In reflective papers students reported that they were most challenged in meeting their partners, determining their partners' abilities and their own role, and assisting their partners in expressing themselves through art. We found that students need instruction in how to speak respectfully to individuals with intellectual disabilities and that students benefit from the time to reflect on their experiences. Our results support the conclusions of previous research on service learning that direct experience with individuals with disabilities can reduce stereotypes and facilitate understanding between individuals.
\end{abstract}




\title{
Individuals with intellectual disabilities: Educators in expressive arts therapy
}

\author{
Karen Caldwell, Ph.D. *, Kathleen T. Brinko, Ph.D., \\ Rebecca Krenz, M.A., Kristin Townsend, M.A. \\ Appalachian State University, Boone, NC 28608, USA
}

\begin{abstract}
The purpose of this qualitative study was to describe students' experiences during their participation in Express Yourself, an expressive arts service-learning program that partners university students from several different programs with adults with intellectual disabilities. In reflective papers students reported that they were most challenged in meeting their partners, determining their partners' abilities and their own role, and assisting their partners in expressing themselves through art. We found that students need instruction in how to speak respectfully to individuals with intellectual disabilities and that students benefit from the time to reflect on their experiences. Our results support the conclusions of previous research on service learning that direct experience with individuals with disabilities can reduce stereotypes and facilitate understanding between individuals.
\end{abstract}

(C) 2008 Elsevier Inc. All rights reserved.

Keywords: Expressive arts therapy; Intellectual disabilities; Service learning; Diversity training

Knowledge of social and cultural diversity is widely understood as fundamental to the preparation of mental health professionals. While numerous practitioners (for example, Baruth \& Manning, 2007; Sue \& Sue, 2003) advocate for and give guidance on incorporating multiculturalism into the coursework of mental health professionals, one type of diversity has received minimal attention - the needs of individuals and families of individuals with intellectual disabilities. An intellectual disability, also known as a developmental disability or mental retardation, involves significant impairment in intelligence and significant limitations in adaptive functioning which started before adulthood. Estimates of the prevalence of intellectual disabilities range from 1 to 3\% (Sulkes, 2006) affecting about 1 in 10 families in the United States (United States Department of Health and Human Services, 2007). According to Special Olympics (2006), people with intellectual disabilities form the largest disability population on earth. Intellectual disabilities can occur in any family, cutting across racial, ethnic, educational, and economic boundaries.

Best practices for the treatment of individuals with intellectual disabilities usually include care by a multidisciplinary team as well as individual and family support services. Community inclusion, increased self-determination, and capacity for self-advocacy are usual goals for treatment. Middleton, Rollins, and Harley (1999) compare the historical and political context of the civil rights of persons with disabilities in the United States with the civil rights movement of African-Americans. They recommend that mental health educators explore alternative ways to develop training 
experiences so that professionals can be more responsive to clients with disabilities. Express Yourself is one such training program, and the purpose of this paper is to describe the experiences of students who are learning to work with individuals with intellectual disabilities through their participation in Express Yourself.

\section{Program description}

Express Yourself (EY) is a series of workshops for children and adults with intellectual disabilities sponsored through Appalachian State University's expressive arts therapy program, art department, and Center for the Visual Arts. Developed out of a passion to create art-based opportunities for their son with Down syndrome, parents Kate Brinko and Jon Kwiatkowski have coordinated this service-learning project for 3 years. The purpose of EY is to engage individuals with disabilities in the arts in one-on-one relationships to meet the following objectives: (a) help participants gain new perspectives, communicate thoughts and feelings, develop interpersonal skills, and enhance general well-being, (b) expose students to special populations, and (c) integrate individuals with disabilities into the community. Sessions are offered approximately once a month and average 10-20 university student participants and 10-20 community participants with intellectual disabilities per session.

Each of the sessions is led by one of the founders of the program, an expressive arts therapist or expressive arts therapist-in-training. Examples of session titles include: "Who are Yoooouuu????" (creating a character, complete with a costume and/or a mask for Halloween); "Where is Your Heart?" (creating a multi-textured body silhouette), and "Creative Moooovement" (dance and creative movement).

A typical session begins with the university students arriving at the designated site. These students possess widely varying levels of training in facilitation and counseling skills. For $1 \mathrm{~h}$ the university students prepare the space, are introduced to the activity planned and their role in it, and are briefed on the range of possible behaviors they may encounter in working with individuals with intellectual disabilities. Then the community participants arrive with their caregivers, and all participants engage in informal introductions over refreshments. After approximately $15 \mathrm{~min}$ the leader convenes the session typically with a "go around" of introductions, and then states how the planned activity relates to daily life.

At this point, the university students and community participants pair themselves for the expressive arts activity which typically lasts $75 \mathrm{~min}$ and utilizes several arts modalities. At the end of the activity, the leader engages the whole group in processing the event. After the community participants leave, the university students stay an additional $30 \mathrm{~min}$ to debrief. Thus, the community members spend $2 \mathrm{~h}$ and the university students spend $3.5 \mathrm{~h}$ at each event.

\section{Expressive arts therapy}

Expressive arts therapy (EAT) is the practice of using multiple modalities of creative expression in an integrated fashion. Thus EAT uses imagery, storytelling, dance, music, drama, poetry, movement, dream work, and/or the visual arts in various combinations to improve mental health. As defined by the Appalachian Expressive Arts Collective (2003), expressive arts therapy:

... is about reclaiming our innate capacity as human beings for creative expression of our individual and collective human experience in artistic form. Expressive arts therapy is also about experiencing the natural capacity of creative expression and creative community for healing. (p. 3)

EAT is rooted in psychotherapy practice and thus is distinctly different from using arts and crafts to promote leisure wellness.

Numerous authors have advocated for creative/therapeutic outlets for individuals with disabilities (for example, see Huang, 2002; Lynch \& Chosa, 1996; Reynolds, 2002). Different modalities of creative arts therapies are reported to be helpful for people with a variety of disabilities including music therapy (Duffy \& Fuller, 2000; Hooper, 2002), drama therapy (Green \& Reinhard, 1995; McKenna \& Haste, 1999), art therapy (Carrigan, 1993; Dalke, 1984; Marriott \& White, 1991; Osborne, 2003; Saunders \& Saunders, 2000; Scanlon, 1993; Tortoreto, 2004), and intermodal therapies (Barret \& Clements, 1997; Wikström, 2005). Reynolds (2002) claims that various modalities can impact individuals with disabilities by facilitating communication, especially of emotions. Thus arts modalities "make use of non-verbal channels of expression, and therefore, may help to convey personal perspectives even where the client does not have effective use of speech (p. 64)". Henderson and Gladding (1998) advocate for including creative arts in counseling as a way to evoke clients' strengths and abilities and provide opportunities to connect diverse groups of people. 
Several researchers advocate for the incorporation of experiential learning in the training of therapists. Ziff and Beamish (2004) report on success in using experiential learning in a course about incorporating arts into counseling. Similarly Carrigan (1994) describes incorporating experiential learning involving individuals with disabilities into a course of training for art therapists. Carrigan's work supports the conclusions of the service-learning research that direct experience with individuals with disabilities can reduce stereotypes and facilitate understanding between individuals with and without disabilities (Eyler, Giles, Stenson, \& Gray, 2003).

\section{Research design}

To extend this small body of literature, we designed a qualitative research project to address the question, "What are the experiences of students learning to work with persons with intellectual disabilities in an expressive arts therapy workshop?" Over the course of a semester, 33 different students enrolled in counseling, family therapy, expressive arts therapy, psychology, and teacher preparation programs participated in four different EY sessions with community adults who had intellectual disabilities.

\section{Identifying our subjectivities and intersubjectivity}

As qualitative researchers, we ourselves were the instrument for data collection and analysis. Early in the project we agreed to help each other acknowledge and monitor our biases and subjectivities. We agreed to pay attention to the feelings we were having as we engaged in EY, and we wrote papers identifying our primary "Subjective I" (Glesne, 1999 ) as a means of becoming more aware of our own lenses for interpreting the experiences of the student participants in EY.

Our interpretive position was shaped by our being a team of four white women who met at a mid-sized university in the southern United States. Much of KB's involvement with EY stems from her "Mom I", her mother self. As a mother of a teen with Down syndrome, KB co-founded EY so that she could make a difference in her small part of the world. As adjunct associate professor in the expressive arts therapy program, she also taught students in the program and supervised the leaders of the EY sessions. KC entered the EY activities in the role of associate professor with a marriage and family therapy program at Appalachian State University. She thus had taught some of the students who participated in the EY program. KT was a graduate student in the expressive arts therapy certificate program and the school counseling program. Initially, she felt strongly that participants with disabilities need access to support services and identified this as her "Justice I" or "Caring I." She also felt passionately about how much the community participants have to offer while acknowledging how difficult it can be for them to express their gifts or to find places where their potential can manifest. "Tentative I" was part of RK's experience because she felt she had not had enough experience with people who have intellectual disabilities to feel completely comfortable with them. All four researchers were participant/observers in the research process.

\section{Research process}

To better understand the experiences of students who participated in EY, our research team (KC, KT, RK, and $\mathrm{KB}$ ) attended four sessions of EY over the course of one semester and, after receiving approval from the Institutional Review Board, collected reflection papers about the experience from 20 students. We took notes on the oral reflections of students in each post-session debriefing, and recorded in writing our observations and experiences of the session immediately after each session. We met immediately after each session to discuss our observations, and audiotaped and transcribed each meeting. The research team routinely sent memos to each other to produce a written record of methodological decisions that were made and how we were interpreting the responses of each other. RK and KT also audiotaped and transcribed their interviews with the founders of the program. Researchers used a computer program, NVivo 1.1 (Qualitative Solutions \& Research, 1999), to assist in data management and analysis.

To begin the coding process, we individually read the students' reflection papers and separately developed initial codes. We then discussed these individual coding systems and jointly developed an initial group coding system. We continued to meet and code the papers from the first two sessions as a group, and we agreed on the definition, modification, and assignment of codes by consensus. During this time, $\mathrm{KC}$ documented coding decisions and changes in the coding system. KC then coded the papers from the last two sessions. 
Based on the outline of codes the team had developed, $\mathrm{KC}$ drafted a narrative and sent it to the student participants, and requested feedback about whether it was representative of their experience. The narrative was then modified based on their feedback (member validation, Lincoln \& Guba, 1985).

While quantitative researchers have come to a consensus around criteria for establishing the quality of a study, qualitative researchers have not. To address issues of quality, we operated out of a position of "intense methodological awareness" (Seale, 1999), maintaining our written memos and records of our decisions about how to proceed. We also reflected on the criteria proposed by Lincoln and Guba (1985) to improve the quality of our project. We hoped to establish credibility through the triangulation of our different perspectives, the use of member validation of our results, and our search for negative instances during our coding. We attempted to establish transferability through writing a detailed, rich description that offers sufficient information for readers to judge the applicability of our findings to other settings. The dependability of our results can be shown through our audit trail of memos, observation notes, and emails which are available for independent review. In regards to authenticity, we acknowledge that there is a range of different realities and that there could be other ways to represent the experiences of students in the EY sessions.

\section{Student participant experiences}

While there are as many narratives as there were individuals who participated in the EY sessions, six themes summarize the responses of students. These themes are: (1) initial reactions, (2) process comments, (3) concluding affective responses, (4) learning about people with intellectual disabilities, (5) learning about self, and (6) learning about the expressive arts process. Pseudonyms are used in the following section to protect the identities of the community participants with intellectual disabilities.

\section{Initial reactions}

Students' initial reactions to participating in EY ranged from apprehension to excitement, and from not knowing what to expect to believing nothing important would happen. Prior to the sessions several students reported feeling tired, or feeling flustered and/or distracted from the stresses of academic and personal lives. Others were excited in anticipation of the event, and several mentioned their enjoyment of the expressive arts process: "I thought that it sounded like a fun idea to work with people and make masks," or "I was excited that we would be making journals and talking about spring, despite the weather outside." However, one student commented that along with feeling excited, she was dreading parts of the process:

When we were setting up, I was dreading all of the dramatics and "pretend", particularly when we had to get in the middle of the circle. However, as soon as the participants got there, I could feel their excitement in the air.

The most frequently reported initial reaction was that of being nervous, and students gave a number of different reasons for their nervousness including being apprehensive about meeting new people, being in a crowd, pairing off for work, being unsure of working with adults, and/or being unsure about how to work with people with intellectual disabilities.

A number of students reported that they found they were able to relax as they met people and began the activities. Students also reported feeling less nervousness after they gained experience with individuals with individual disabilities. As one of our research team members (KT) observed: "Apprehension exists in all individuals and groups regardless of age and developmental level and ... when faced, feelings of hesitation can create a powerful opportunity for change and development to occur."

\section{Process comments}

Students' papers included descriptions of what they experienced during the session. These descriptions centered around the themes of finding a partner, determining the disabled participants' abilities, and discerning their own role. 


\section{Finding a partner}

Most EY sessions are organized around the principle that individuals from the community with intellectual disabilities are partnered with someone who can assist them in art making. The founders of the program refer to the initial 15 min of informal introductions over refreshments as the "Express Yourself dance," an apt metaphor for the relational process of finding a partner with whom to engage in a time limited activity. Half of the university students reflected on the process of finding a partner. One student wrote:

I thought we would just be assigned a partner and then we would work with them on how to make the journal, but I was mistaken. We were told to "mingle" with the participants to see who we wanted to work with. I was again scared. I did not know what to say or how to act, so I just sat down between a man and a woman. The woman did not seem to want to talk, but the man on the other hand was interested in having a conversation. So, he became my partner.

Sometimes the university students initiated conversations to find a good fit with a partner, and other times, the individuals with intellectual disabilities were the initiators. One student whose partner initiated the partnering process wrote:

I've never had a whole lot of experience with people with disabilities, and especially adults. I knew I was in the right place, though, when Maureen ran up to me as soon as she got there, threw her arms around my neck, and said with a big smile on her face, "Hey girl, you wanna be my partner today?" It felt so good to get a hug right off the bat, and that put me at ease.

At other times students found themselves "de-partnered":

I felt connected to him [one of the participants], and helped him in the beginning to get buttons and fabric. We brought his material back to the table and I noticed that two of the helpers who came with him were already sitting on each side of him. I assumed that they were used to helping him, probably had formed a good relationship, so at that point I backed away and began to look for someone else who needed help.

Students who had attended previous EY events used their prior experiences in the partnering process. One such student wrote: "Elijah arrived on one of the buses; I had worked with him on my first day of Express Yourself. He gravitated towards me. I was happy to work with him and enjoyed continuing our conversations from before."

\section{Determining participants' abilities and one's own role}

A major part of the EY process for student participants appeared to be the process of determining the ability levels and motivations of the participants with intellectual disabilities. Three-fourths of the students' reflection papers addressed this process. The individuals with intellectual disabilities who attended EY had a range of cognitive, sensorimotor, and interpersonal skills, and students found that they could not make sweeping assumptions about the abilities of the participants.

One student explained her apprehension about attending EY in this way:

I was less nervous attending my second Express Yourself workshop. I still am somewhat nervous working with adults because I never know what to expect. There are so many disabilities that people can have and you can never be sure whom you will be working with. I was nervous that I would offend someone by trying to help too much.

Hand in hand with the process of determining the capabilities of the disabled participants was the process of discerning one's role with a disabled partner. It was not unusual for student participants who are new to the EY process to be unable to readily determine who the "disabled" participants were. For example, one student wrote, "I was surprised by how many of the participants were high-functioning, and in fact, I was not able to differentiate between the participants and the caretakers." However, some of the participants' disabilities were evident early in the process. One student described the process of working with her partner in this way:

This time I worked with Dan, who is not extremely verbal. Without knowing the different reasons why he couldn't, or wouldn't talk, I decided to carry on a normal conversation with him, and to let him jump in wherever he chose. 
Another student wrote about the physical limitations of her partner and the role she took in the expressive arts process in this way:

Our task was to make and decorate a creative journal, and because of Dorothy's physical needs, I ended up having to do most of the cutting, gluing, and assembling of the journal. That being said, as soon as I had done most of the initial getting-us-started, she really blossomed at the decorating stage of the process, and sent me scurrying off to find sparkles and doodads and such while she plowed ahead.

The disabilities of some of the community participants became clearer as the students became involved in activities, and this changed understanding called forth different roles for the students. For example, one student wrote:

I floated for a bit, finding that everyone was pretty well paired. Then I looked over to find that no one was helping Francine. She had no materials but the journal and the bucket of stickers sitting in front of her, and boy did she love those stickers. I asked if she wanted to look at any other materials to decorate her journal. She said, "No", so I helped her with her stickers because she was having a hard time sticking them on her journal. ... I realized that her sensorimotor skills were not fully developed and could tell she was having trouble with the stickers and wasn't able to cut fabric or yarn.

After reflecting on the interaction, this student wrote: "From hearing others' experiences, I realized that there are [other] ways to help out, by listening to what they want and doing things they may not be able to."

\section{Concluding affective responses}

Many students processed how they felt after the sessions. Responses ranged from positive emotions (enjoyment, amazement, and wonder) to negative or more difficult emotions (isolated, frustrated, scared, and uncomfortable).

\section{Enjoyment, amazement, and wonder}

Most of the student participants found the sessions pleasurable; $65 \%$ of the reflection papers had references to how personally enjoyable the EY sessions were. Many used the word "fun" to describe their experience, and referred to having fun watching the participants with intellectual disabilities have a good time, having fun with the expressive arts activities, having fun interacting with the participants with intellectual disabilities, or some combination of these elements. For example, one student wrote about the enjoyment of a spontaneous moment with her partner:

At one point the music spoke to Michelle and she grabbed my hand and drug me in the middle of the room to dance. I was stunned, excited and hysterically laughing the whole time; nothing mattered but having a great time and being with Michelle in the moment.

While "fun" was the most frequently expressed affective response to the EY sessions, almost half of the students wrote that they felt thankful or were appreciative of the opportunity to participate, about a fourth of the students wrote about wanting to participate again, and about a fifth wrote about feeling sad to see their partner leave with hopes of seeing them again. Students gave several reasons for their appreciation, such as the relationship they had with their partner, the opportunity to interact with individuals with intellectual disabilities, learning about the expressive arts therapy process, or being reminded to be more present in the moment. For example, one student wrote, "I am glad that I was able to participate in EY because I have never had an opportunity to interact with adults with developmental disabilities." Another student wrote, "I appreciated being reminded to live my life to the fullest, enjoying the simple things like the smell of rain."

Another common affective experience for students was that of wonder or amazement at the EY process and at the reactions of all the participants. In particular, students noticed when shy or withdrawn participants decided to try something new. In one session, a student noted, "I was especially excited about Chad singing his song since I had noticed how withdrawn he seemed when he first came to the event." One of the student researchers (RK) noted the following about a young man with an intellectual disability:

When it came time for the group to participate in a "name bath" where one person stands in the middle of the circle and listens to their name being sung out by everyone in the circle, he decided to stand in the middle in view of everyone. He also participated fully in the other activities that included acting out your masked character 
and mirroring the movements of your partner. I was not even aware that this young man had social anxiety until his teacher informed me that this social interaction for him was a very big deal. Apparently he never behaved in such a socially relaxed manner at [a local sheltered workshop]. At the end of the session, he expressed that he was really glad to have met new people this day.

In addition to amazement, students wrote of being emotionally touched in a more general way, usually related to the openness of the participants. One student wrote, "I was moved through the [the participants' with intellectual disabilities] engagement in a genuine and honest expression of feelings, reflecting their thoughts by leading to actions with one another expressing their true thoughts and feelings." Another student wrote, "I was completely overwhelmed by the affection of the group; they didn't hold back, they didn't hold grudges."

\section{Isolated, frustrated, scared, uncomfortable}

While most student participants reported positive experiences, some students experienced more difficult feelings. For example, one student wrote:

I noticed myself feeling isolated while Barbara and I worked. Many of the participants and helpers were engaged in small or medium-sized groups of people while working, but Barbara was quite introverted and quieter and so we worked as just the two of us.

Other students expressed frustration over difficulty in communicating with their partner. One student explained:

There were a few times when I couldn't understand her. She got frustrated with me and I tried to not get frustrated with the situation. That made me feel really bad, but when I finally figured out what she was saying and was able to say it back to her, it made her light up and feel so good. I can't imagine what it must be like to go misunderstood all the time. But nevertheless, we had a great time together.

Another student experienced frustration at the process of the session:

I realize now that it feels, to me, like we were perhaps engaging the participants in a situation which I experienced more as "arts and crafts," and this caused me to wonder whether the bigger picture of expressive arts therapy was perhaps missing from the process. I wonder now: 'What would have helped to create a deeper experience for me as a helper?'

One student experienced fear during a session in which one of the participants with an intellectual disability became emotional:

The scariest part of the day was when Ella started to cry during the song. I felt like it was my fault, and I just KNEW I had made an enemy out of her. But just a few minutes later, she gestured for me to come and sit beside her.

These experiences of feeling isolated, frustrated, scared or uncomfortable became points for personal growth and learning, as did the entire EY experience.

\section{Learning about individuals with intellectual disabilities}

While students frequently used the words "zest for life" and being "in the moment" when referring to what they learned about working with individuals with intellectual disabilities, their writing ranged from both positive and negative stereotypes on one hand to valuing the unique qualities of individuals on the other hand. One student who expressed a great deal of fear towards those with disabilities began to identify her fear as based in part on a sense of guilt that she hadn't provided enough support for a family member with a disability. One group of students described the community participants as a group in global terms such as "sweet," "nice," "carefree," or "special" without referring to the unique capabilities and preferences of the individuals who attended the sessions. Other students wrote about shifting from a negative stereotype to a more positive one as the following example indicates:

Some people perceive mentally handicapped people as being weird and they have no idea what's going on. I happened to be one of those people when I was younger and more close-minded. Now, I know that they are very smart people and yes they do know what's going on around them. 
After one session, caregivers complained that some of the students were "talking down" to the participants with intellectual disabilities, an indication that the students were operating out of excessively low expectations or other stereotypical perceptions. KB and EY session leaders made a point in subsequent sessions to orient students about this issue. One student reported:

I learned that it is important to not degrade them and to treat them the same as I would anyone else. ... While painting and coloring with Linda I noticed that she liked to talk about topics that any other adult would talk about. She liked to talk about her boyfriend, where she was from, and where she was going for her next vacation.

This student was one of several who focused on the individuality of participants and who valued individuals with intellectual disabilities as unique human beings. These students usually wrote about an individual with whom they worked, their preferences and approach to the art making. One student researcher (KT) concluded:

It becomes fundamentally important not to underestimate the capabilities of people with various levels of development. Though I have worked with many individuals with various ability levels, I always try to remind myself that each person I come in contact with has a unique set of abilities that makes that one person unique. I try not to generalize all people with autism or Down syndrome to the same place in my thoughts or interactions with them.

\section{Learning about self}

Students' knowledge about themselves increased as a result of participating in the EY sessions. Many wrote about feeling better about themselves, feeling greater self-efficacy, or feeling freer to be authentic. For example, one student wrote, "After relaxing, I realized that I could do this." Another wrote, "Their openness and good attitudes made me feel more comfortable being myself than I have in a long time." One student suggested that "greater feelings of self-worth" and "more hope" would be one of the findings from this research project. In response to the joie de vivre her disabled partner exhibited, another student wrote, "She made me wonder why I can get so stressed about everything going on in my life," and concluded that she hoped she would be able to "look back on the experience in times of stress" and remember the positive role models for coping with difficulty. In a similar fashion, another student wrote:

Being with people who value such simple aspects of life, like curly yarn or fishing in the summertime, made me step outside myself for awhile. I started to think of the simple things in my life that I overlook or under-appreciate.

Another student wrote on this theme in more detail:

I had a very stressful week last week, and I have a very stressful rest of the semester coming up. But for some reason, I was in the best mood on Friday when I left. I don't think I complained about a thing for the rest of the day. Even my fiancé noticed; he knows how stressed out I have been and he was wondering why I was in such a good mood! I think something about participating in Express Yourself affected my day in a very positive way. I think a lot of it was because I was able to cut loose and just be myself, and I had an accepting group of people to do it with.

Several students concluded that they had learned that they enjoyed working with the intellectually disabled population and wanted to find work with them.

Several students wrote about major shifts in their perspectives. For example, RK wrote that before she observed a participant who was diagnosed with social anxiety become outgoing in the group, she had not observed people making major changes: "The way I will apply this information to my own practice of therapy is by first of all thinking positively about change: that it does happen." Another student wrote about how the experience led her to redefine her sense of self in an existential sense:

Attending the masks workshop was an eye opener for me. I have been around disabled people a lot but never have I felt the way I did during this workshop. ... After the workshop I asked myself, "Who is really normal among the human race and what is normal anyway"? I pondered this thought in my mind for days. What do I have or possess in life that the "disabled" don't have? I am thinking in perspective of life's essential needs, the holistic aspects of body, mind and soul, (let's not forget love). 


\section{Learning about expressive arts}

Approximately half the students reported that they expanded their understanding of the expressive arts therapy process. Several wrote about learning a new technique and how they could apply it in the settings for which they were preparing. A number of students also commented about how the activities were useful to help people "open up and be themselves," to "facilitate easy conversation," to "feel more at ease," and to "express themselves fully" in the counseling or therapy setting.

Several students in the expressive arts therapy program wrote reflections integrating the theory they were learning in their classes with their experience of EY. One student wrote:

I learned a lot from this experience. It has especially helped to stir up some thoughts about what works and what doesn't work, for me, in expressive arts therapy workshop settings. And, this experience also calls me to look at a pertinent class question: what is my approach to expressive arts therapy and how can I help to cultivate this way?

Another student wrote about modifying some of her ideas:

My philosophy with expressive arts is to keep out of the art making as much as possible, and to let the artist take control, stepping in as little as possible. But after working with Jaclyn, I would like to work with her again and the next time provide a second set of hands for her to create with.

A third student noted that a session went well because the facilitators allowed for a "space of spontaneity and a giving in to the process." In this session:

My favorite part of the workshop was the drumming section with which we played our percussions according to certain emotions brought about by [the facilitator's] story. I felt this was when participants were most involved and most present in the workshop. My guess here is that this story/percussion section challenged us to use our imaginations the most, connecting our internal visions of the story being told with an external means of expression (the instruments we each had in our hands). This part of the workshop is what I believe in most about the true value of expressive arts therapy; this being the exercises of using external means to express our inner worlds, be it our visions, emotions, or anything else that involves imagination and the unconscious. It also served as a simple and more fun way for the developmentally disabled folk to be present in the moment.

\section{Conclusions}

University students participating in EY sessions found the experience to be an effective avenue for learning about individuals with intellectual disabilities, themselves and expressive art therapy. The challenges of finding a partner, determining the partners' abilities and their own role, and assisting partners in expressing themselves through art provided a powerful and enjoyable learning experience.

\section{Implications}

The EY program is an innovative way to incorporate experiences with individuals with intellectual disabilities into the training of mental health professionals. Our study found the program to be effective in sensitizing students to the issues faced by individuals with intellectual disabilities, confirming studies that found service learning to reduce stereotypes and facilitate cultural understanding (Eyler et al., 2003).

While EY involved educators associated with an expressive arts therapy program, classroom instructors wishing to replicate this type of program may partner with theater, art, and/or music therapy programs. Opportunities may also exist for partnerships with local schools, arts institutions, or Special Olympics. One author (KB) had experience with university students partnering in sports events with individuals with intellectual disabilities. Anecdotal reports support the possibility that these kinds of activities are also powerful experiential learning opportunities that introduce university students to individuals with intellectual disabilities.

For educators interested in adapting or replicating parts of the EY program, we suggest two key components of the process. First, students need to be cautioned about stereotyping and need to be instructed in how to speak respectfully 
to individuals with intellectual disabilities. One of the caregivers reported that she was frequently mistaken for an individual with an intellectual disability and "talked down to" because she used a cane and had difficulty walking. Van der Klift and Kunc (1994) note that most people tend to perceive an individual with a disability primarily in terms of that disability and not as an individual with capabilities, needs, and desires. We found that the students appreciated being sensitized to the issue, and we experienced an improvement in the quality of the interaction between the university students and community participants with intellectual disabilities when instructions included examples of speaking to participants respectfully.

A second key component of a successful experience is reflection (Hecht, 2003). In the EY program, students were provided an opportunity for both oral reflection (in the debriefing immediately following the expressive arts therapy session) as well as written reflection in the papers submitted to their instructors and to the researchers. In one class students were instructed to reflect on: (1) any previous experiences with individuals with intellectual disabilities, (2) thoughts and feelings in anticipation of, during, and after the experience, (3) "video-tape" descriptions of their interactions ("If a video-tape were recording your interactions, what would be recorded?"), (4) the meanings students made out of what happened, and (5) general impressions and concerns. Structured reflections encourage students to develop their abilities to self-monitor their reactions to clients and their experiences, an important skill for therapists and other helping professionals.

We encourage educators to further investigate the use of expressive arts as a means of building relationships with and supporting the creative expressions of individuals with intellectual disabilities. Research documenting the effectiveness of expressive arts therapy is still in its beginning stages, so additional case studies and other qualitative research strategies are warranted. Also needed are studies to determine the necessary elements for successful collaborations between artists and educators to guide the advocacy for and planning of innovative programs involving students and individuals with intellectual disabilities.

\section{References}

Appalachian Expressive Arts Collective. (2003). Expressive arts therapy: Creative process in art and life. Boone, NC: Parkway Publishers.

Barret, D. B., \& Clements, C. B. (1997). Expressive arts programming for older adults both with and without disabilities: An opportunity for inclusion. In T. Tedrick (Ed.), Older adults with developmental disabilities and leisure: Issues, policy, and practice (pp. 53-61). NY: Haworth Press.

Baruth, L. G., \& Manning, M. L. (2007). Multicultural counseling and psychotherapy: A lifespan perspective (4th ed.). NY: Merrill.

Carrigan, J. (1993). Painting therapy: A Swiss experience for people with mental retardation. American Journal of Art Therapy, 32(2), 53-58.

Carrigan, J. (1994). Attitudes about persons with disabilities: A pilot program. Art Education, 47(6), 16-21.

Dalke, C. (1984). There are no cows here: Art and special education together at last. Art Education, 37(6), 6-9.

Duffy, B., \& Fuller, R. (2000). Role of music therapy in social skills development in children with moderate intellectual disability. Journal of Applied Research in Intellectual Disabilities, 13(2), 77-89.

Eyler, J. S., Giles, D. E., Stenson, C. M., \& Gray, C. J. (2003). At a glance: What we know about the effects of service-learning on college students, faculty, institutions, and communities, 1993-2000. In Introduction to service-learning toolkit: Readings and resources for faculty (2nd ed., pp. 15-19). Providence, RI: Campus Compact.

Glesne, C. (1999). Becoming qualitative researchers: An introduction (2nd ed.). NY: Longman.

Green, M. Y., \& Reinhard, R. (1995). When art imitates life: A look at art and drama therapy. Public Welfare, 53(2), $34-43$.

Hecht, D. (2003). The missing link: Exploring the context of learning in service-learning. In S. H. Billing \& J. Eyler (Eds.), Deconstructing service learning: Research exploring context, participation and impacts (pp. 25-49). Greenwich, CT: Information Age Publishing.

Henderson, D., \& Gladding, S. (1998). The creative arts in counseling: A multicultural perspective. The Arts in Psychotherapy, 25(3), $183-187$.

Hooper, J. (2002). Using music to develop peer interaction: An examination of the response of two subjects with a learning disability. British Journal of Learning Disabilities, 30(4), 166-170.

Huang, Q. (2002). Creative therapy and initiative activities among people with developmental disabilities in public facilities. Journal of Disability Policy Studies, 13(3), 138-143.

Lincoln, Y. S., \& Guba, E. (1985). Naturalistic inquiry. Beverly Hills, CA: Sage.

Lynch, R. T., \& Chosa, D. (1996). Group-oriented community-based expressive arts programming for individuals with disabilities: Participant satisfaction and perceptions of psychosocial impact. Journal of Rehabilitation, 62(3), 75-82.

Marriott, B., \& White, M. P. (1991). The impact of art therapy on the life of a woman who was mentally retarded. American Journal of Art Therapy, $30(1), 10-16$.

McKenna, P., \& Haste, E. (1999). Clinical effectiveness of dramatherapy in recovery from neuro-trauma. Disability and Rehabilitation, 21(4), $162-174$.

Middleton, R. A., Rollins, C. W., \& Harley, D. A. (1999). The historical and political context of the civil rights of persons with disabilities: A multicultural perspective for counselors. Journal of Multicultural Counseling and Development, 27(2), 105-120.

Osborne, J. (2003). Art and the child with autism: Therapy or education? Early Child Development and Care, 173(4), 411-423. 
Qualitative Solutions and Research. (1999). NUD-IST Vivo (Nvivo) [Computer software]. Melbourne, Australia: Qualitative Solutions and Research Pty. Ltd.

Reynolds, F. (2002). An exploratory survey of the opportunities and barriers to creative leisure activity for people with learning disabilities. British Journal of Learning Disabilities, 30(2), 63-67.

Saunders, E. J., \& Saunders, J. A. (2000). Evaluating the effectiveness of art therapy through a quantitative, outcomes-focused study. The Arts in Psychotherapy, 27(2), 99-106.

Scanlon, K. (1993). Art therapy with autistic children. Pratt Institute Creative Arts Therapy Review, 14, 34-43.

Seale, C. (1999). The quality of qualitative research. Thousand Oaks, CA: Sage.

Special Olympics East Asia. (2006). What is intellectual disability? Retrieved September 10, 2007, from http://www.specialolympicseastasia. org/English/About_SOEA/mr.html.

Sue, D. W., \& Sue, D. (2003). Counseling the culturally diverse: Theory and practice (4th ed.). NY: John Wiley \& Sons.

Sulkes, S. B. (2006). Learning and development disorders. In M. H. Beers (Ed.), The Merck manual of diagnosis and therapy (pp. 2483-2495). Whitehouse Station, NJ: Merck Research Laboratories.

Tortoreto, M. A. (2004). The power of A.R.T. The Exceptional Parent, 34(7), 52-53, 55-56

United States Department of Health and Human Services Administration for Children and Families. (2007). Fact sheet, The President's committee for people with intellectual disabilities. Retrieved February 7, 2007, from http://www.acf.hhs.gov/programs/pcpid/pcpid_fact.html.

Van der Klift, E., \& Kunc, N. (1994). Beyond benevolence: Friendship and the politics of help. In J. S. Thousand, R. A. Villa, \& A. I. Nevin (Eds.), Creativity and collaborative learning: A practical guide to empowering students and teachers (pp. 391-401). Baltimore, MD: Brookes.

Wikström, B. (2005). Communicating via expressive arts: The natural medium of self-expression for hospitalized children. Pediatric Nursing, 31(6), $480-485$.

Ziff, K., \& Beamish, P. (2004). Teaching a course on the arts and counseling: Experiential learning in counselor education. Counselor Education and Supervision, 44(2), 147-159. 